\title{
Ischaemic left ventricular failure: evidence of sustained benefit after 18 months' treatment with xamoterol
}

Else Vigholt-Sørensen, Ole Faergeman

\begin{abstract}
The long term efiects of treatment with xamoterol in 14 patients aged 44-73 with mild to moderate heart failure as a result of ischaemic heart disease are reported. After 18 months' treatment with xamoterol, patients were assessed in a randomised double blind crossover comparison of xamoterol $(200 \mathrm{mg}$ twice a day) and placebo, each given for one month. Compared with placebo, xamoterol significantly increased exercise duration and work done on a bicycle ergometer and reduced the maximum exercise heart rate. Assessment of symptoms and activities at 12 months by visual analogue and Likert scales showed a trend towards the relief of symptoms of breathlessness and tiredness and an improvement in activity. There was an improvement in the clinical signs of heart failure and no haemodynamic deterioration over a 12 month period as assessed by ejection fraction.

The improvement in exercise tolerance, symptoms, and activities was sustained for 18 months without side efiects or development of tolerance.
\end{abstract}

Chronic heart failure affects approximately $4 \%$ of the elderly population and is often a result of myocardial infarction. ${ }^{1}$ In the Framingham study $39 \%$ of the patients with chronic heart failure had coronary artery disease. ${ }^{2}$ In patients with ischaemic left ventricular dysfunction treatment with xamoterol (for up to 3 months) had a beneficial effect. ${ }^{3-5}$
Xamoterol (Corwin), a partial agonist at the $\beta_{1}$ adrenoceptor, stabilises the response of the heart to sympathetic drive. ${ }^{67}$

It has been suggested that treatment with drugs that have stimulant activity at the $\beta$ adrenoceptor may be beneficial in the short term but does not show sustained benefit because of a reduction in $\beta$ receptor density. ${ }^{8}$

The aim of this study was to reassess the effect of withdrawal of xamoterol after chronic treatment for 18 months in patients with mild to moderate heart failure.

\section{Patients and methods}

DESIGN

The study had two phases. Phase I was. an open study with active treatment (xamoterol $200 \mathrm{mg}$ twice daily) for 18 months. Phase II was a double blind, placebo controlled, crossover study, with treatment periods of 4 weeks (figure). Patients continued treatment in an open study. The protocol was approved by the ethics committee of the Århus Amtssygehus and the study was conducted in accordance with the revised Declaration of Helsinki. Patients gave their verbal consent to inclusion in the study.

\section{PATIENTS}

We selected patients aged 44-73 years with symptoms of dyspnoea or fatigue or both on exercise-that is mild to moderate heart failure (New York Heart Association class IIIII). They had previously completed a short term placebo controlled study. ${ }^{9}$ Patients with severe heart failure (class IV) were excluded.

Other exclusion criteria included: pre-
Department of Internal Medicine and Cardiology, Arhus Amtseygehus, Arhus, Amtseyge E Vigholt-Sørensen O Faergeman

Correspondence to Dr Else Vigholt-Sorensen Department of Cardiology, Skejby Hospital 8200 Arhus N, DK Denmark

Accepted for publication 27 February 1990

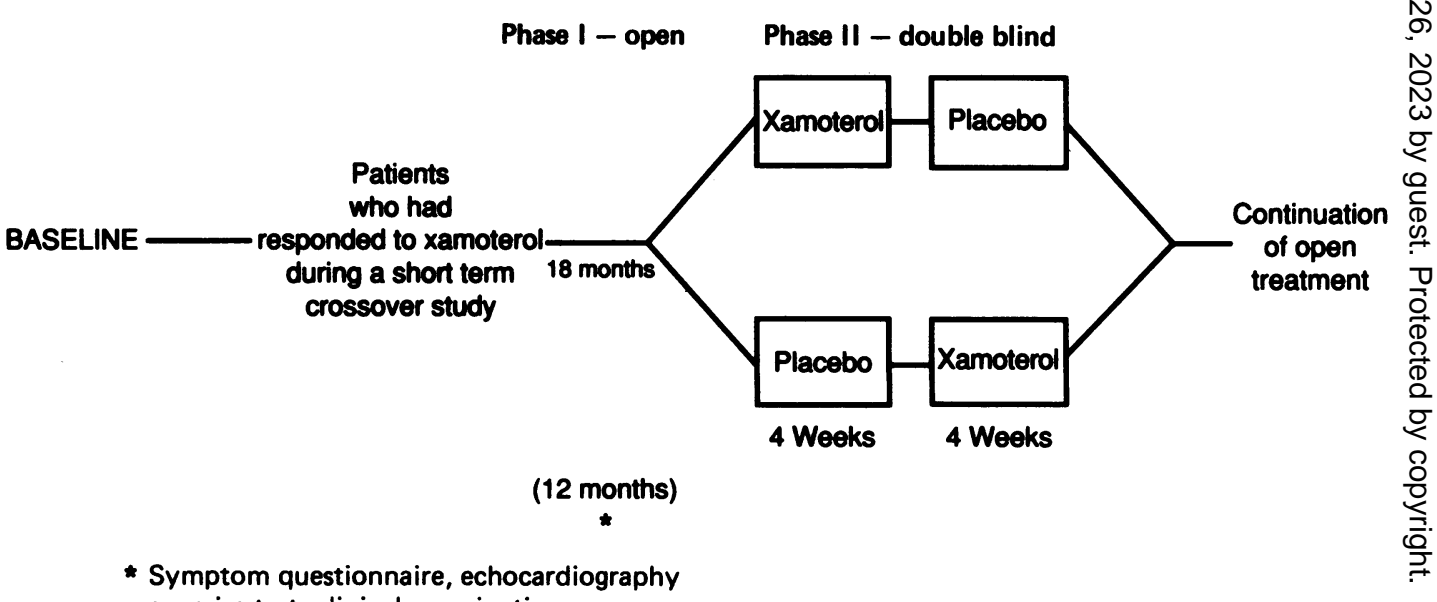
exercise test, clinical examination 
menopausal women; pulmonary disease causing breathlessness on exercise; sinus tachycardia $>90$ beats per minute; any arrhythmia requiring treatment; aortic or mitral stenosis; hypertrophic obstructive cardiomyopathy; serious non-cardiac diseases; inability to complete 3 minutes of the exercise protocol; concurrent treatment with digitalis, $\beta$ blockers, vasodilators (hydralazine, prazosin), angiotensin converting enzyme inhibitors, calcium antagonists, and antiarrhythmic agents. Thiazide diuretics at any dose were permitted but daily doses were limited to $80 \mathrm{mg}$ of frusemide, $2 \mathrm{mg}$ of bumetanide, and $100 \mathrm{mg}$ of spironolactone.

\section{METHODS}

Clinical examination

Patients were assessed every 3 months during phase I and at the end of each monthly treatment period in phase II. This clinical examination included auscultation of the heart and lungs; measurement of heart rate, blood pressure, jugular venous pulse; and assessment of hepatomegaly and peripheral oedema.

\section{Quality of life assessments}

Symptoms and daily activities were assessed at 12 months by Likert and visual analogue scale questionnaires. Each questionnaire included questions on the degree of limitation by breathlessness, tiredness, chest pain, and palpitation. Patients recorded their answers on the visual analogue scale with a vertical mark through a $100 \mathrm{~mm}$ horizontal line marked at the two extremes "not at all" and either "very much" or "a great deal". For the Likert scales answers were rated on a 4 or 5 point scale by the physician. ${ }^{9}$

\section{Effort tolerance}

Effort tolerance was assessed by a symptom limited exercise test on a Siemens bicycle ergometer that started at $50 \mathrm{~W}$ and increased by $25 \mathrm{~W}$ every 3 minutes. Heart rate and blood pressure were measured at the end of each 3 minute period, when exercise stopped, and at 1 and 3 minutes after exercise. The duration of exercise was recorded and the total work done calculated. The reasons for stopping exercise were recorded.

\section{Echocardiography}

The ejection fraction was measured at baseline and after 12 months by echocardiography. Patients were examined with an Aloka scanner while supine.

\section{STATISTICAL ANALYSIS}

Analysis of variance was used to detect any differences between treatments. Any significant treatment effect was assessed by an $F$ test. $P$ values $<0.05$ were regarded as significant. Data generated during the open phase (phase I) were expressed as means and standard error or medians.

\section{Results}

CHARACTERISTICS AT BASELINE

After completing a short term placebo controlled study, ${ }^{9} 18$ of the 21 patients who had responded continued in this long term study. Table 1 lists the characteristics of the patients (mean age 62.2 years (range 44-73), 12 men and six women). Seventeen patients were classed in New York Heart Association II and one in class III. The aetiology of the heart failure in this group of patients was ischaemic heart disease. All patients had a history of myocardial infarction.

\section{WITHDRAWALS}

Three patients withdrew during phase I. One patient withdrew after 3 months because of deterioration and psychological problems (he later died of a myocardial infarction), one completed 6 months but failed to attend his next appointment, and one patient died after 9 months' treatment because of a lung tumour that had been present before entry to the study. Data from one patient were not included in the analysis because his treatment was not continuous. The analysis therefore includes data from 14 of the 18 patients initially entered in the study. (Since the end of the study two patients have died after 30 and 33 months' treatment. Twelve patients are continuing treatment.)

\section{EXERCISE TEST}

Both exercise duration and work done were significantly higher on xamoterol than placebo after treatment for 18 months (table 2). Eleven out of 14 patients exercised for longer on xamoterol; the mean difference in exercise duration was 61.4 seconds $(p<0.05)$. The increase in the amount of work done was $6.3 \mathrm{~kJ}$ $(p<0.05)$. The maximum exercise heart rate was significantly reduced from $129.5(2 \cdot 3)$ seconds on placebo to $112 \cdot 3(2 \cdot 3)$ seconds on xamoterol $(p<0.0005)$. The main reason that patients stopped exercise was dyspnoea, accompanied by fatigue in some patients. Compared with baseline the mean exercise duration after 18 months' treatment was not significantly different. However, after 1 month's treatment with placebo the exercise duration was significantly reduced.

Table 1 Characteristics of patients at baseline

\begin{tabular}{lc}
\hline Male, female & 12,6 \\
Age (yr) mean (range) & $62 \cdot 2(44-73)$ \\
NYHA class & 17 \\
II & 1 \\
III & 18 \\
Symptoms: & 9 \\
Dyspnoea & 13 \\
Fatigue & 5 \\
Angina pectoris & \\
Peripheral oedema & 17 \\
Medication at entry: & 1 \\
Diuretic & 5 \\
Long-acting nitrates & \\
Glyceryl trinitrate & 11 \\
Signs of heart failure: & 1 \\
Basal crepitations & 2 \\
Hepatomegaly & 7 \\
Raised jugular venous pulse & \\
Enlarged heart on chest $x$ ray & 18 \\
Past medical history: & 1 \\
Myocardial infarction & 1 \\
Ventricular aneurysm & \\
Hypertension & \\
\hline
\end{tabular}


Table 2 Exercise results $(n=14)$

\begin{tabular}{llcc}
\hline Variable & Baseline & Xamoterol & Placebo \\
\hline Exercise duration (s) & $419 \cdot 7(43 \cdot 5)$ & $441 \cdot 1(15 \cdot 6)^{\star}$ & $379 \cdot 7(15 \cdot 6)^{\star}$ \\
Work done (kJ) & $30 \cdot 2(4 \cdot 7)$ & $31 \cdot 8(1 \cdot 7) \dagger$ & $25 \cdot 5(1 \cdot 7) \dagger$ \\
Heart rate at maximum exercise (beats/min) & $125 \cdot 6(5 \cdot 2)$ & $112 \cdot 3(2 \cdot 3) \ddagger$ & $129 \cdot 5(2 \cdot 3) \ddagger$ \\
\hline
\end{tabular}

$p=\star 0 \cdot 016 ;+0 \cdot 02, \ddagger 0 \cdot 0002$.

SYMPTOMS AND DAILY ACTIVITIES

Table 3 shows the results with the Likert scales. Those patients who were not troubled by a particular symptom throughout the study have not been included in this analysis. Apart from questions on sleep the answers to every question tended to favour xamoterol, particularly in terms of tiredness, breathlessness, speed and difficulty with walking, and difficulty with daily tasks. Improvement in tiredness and breathlessness was confirmed by assessment with the visual analogue scales (table 4). Patients also reported not having to rest as often while doing daily tasks.

\section{EJECTION FRACTION}

The mean ejection fraction at baseline was 43.8 $(4 \cdot 2) \%$ and was not changed after 12 months $(43 \cdot 3(3 \cdot 2 \%))$.

\section{CLINICAL SIGNS OF HEART FAILURE}

At entry 11 of the 14 patients had one or more signs of heart failure. The most frequent sign of heart failure was basal creptitations (eight patients); after 18 months no patients presented with this sign.

\section{CONCURRENT TREATMENT}

All but one patient were receiving diuretics. None of the patients needed an increase in concurrent treatment for heart failure over the 18 month period of the study.

\section{ADVERSE EFFECTS}

There were few adverse comments during the study. Most comments related to symptoms of heart failure - that is, dyspnoea, fatigue, pain in the chest, and tiredness. In addition, two patients said they "felt unwell" (in one case a common cold), two patients complained of palpitation, and one patient developed idiopathic hypercalcaemia that reverted to normal within a few months while he was still taking xamoterol.

\section{Discussion}

The effect of xamoterol has been established

Table 3 Patients ( $n$ ) with symptoms and impairment of activities at baseline and after 12 months' treatment

\begin{tabular}{llccc}
\hline & & \multicolumn{3}{c}{ After 12 month' treatment } \\
\cline { 5 - 6 } & At baseline $(n)$ & Better & Same & Worse \\
\hline Tiredness & 14 & 9 & 4 & 1 \\
Breathlessness & 14 & 11 & 3 & 0 \\
Chest pain & 13 & 7 & 4 & 2 \\
Palpitation & 10 & 5 & 2 & 3 \\
Difficulty walking & 13 & 9 & 3 & 1 \\
Speed of walking & 14 & 13 & 1 & 0 \\
Difficulty with daily tasks & 13 & 10 & 1 & 2 \\
Speed of doing daily tasks & 14 & 2 & 11 & 1 \\
Mood & 10 & 4 & 5 & 1 \\
Sleep & 8 & 3 & 1 & 4 \\
\hline
\end{tabular}

Table 4 Median values ( $\mathrm{mm}$ ) for visual analogue scales (for 11 patients)

\begin{tabular}{lll}
\hline & Baseline & $\begin{array}{l}\text { After 12 months' } \\
\text { xamoterol treatment }\end{array}$ \\
\hline Tiredness & $24 \cdot 0$ & $8 \cdot 0$ \\
Breathlessness & 20.0 & $6 \cdot 0$ \\
Chest pain & 4.0 & $5 \cdot 0$ \\
Palpitation & 4.0 & $4 \cdot 0$ \\
\hline
\end{tabular}

in several studies lasting up to 3 months. ${ }^{3-5}$ This study showed that clinical benefit is still maintained after 18 months' treatment with xamoterol.

Over a period of 18 months patients with mild to moderate heart failure would be expected to show signs of deterioration. For example Swerdlow et al have shown that as cardiac failure progresses the prognosis worsens. ${ }^{10}$ In this present study exercise capacity during 18 months did not change from baseline. However, withdrawal of active treatment followed by 1 month of treatment with placebo significantly reduced exercise duration (by 61.4 seconds-equivalent to $6.3 \mathrm{~kJ}$ of work done). These results confirm that efficacy is still demonstrable after 18 months' treatment with xamoterol. After xamoterol was stopped there was no evidence of a sudden deterioration, which suggests there is no rebound effect. In addition to the maintenance of exercise capacity, other measurements indicate that there was no deterioration during the study. The most frequent sign of heart failure at baseline-basal crepitations-was not reported for any patient after 18 months' treatment; no patients needed an increase in concurrent treatment; at 12 months there was no evidence of haemodynamic deterioration as assessed by ejection fraction, and assessment of symptoms and activities at 12 months by visual analogue and Likert scales showed a trend towards a relief of symptoms of breathlessness and tiredness and an improvement in activity.

Apart from xamoterol, long term treatment of heart failure with drugs that have a significant stimulant action on $\beta$ adrenoceptors has been unsuccessful (for example pirbuterol, prenalterol). ${ }^{10-12}$ Only in patients with ischaemic heart disease studied by Glover et al were any long term beneficial effects of prenalterol seen-effects attributed to the reduction in exercise heart rate and consequent antiischaemic action of prenalterol. ${ }^{13}$

This lack of a sustained effect has been attributed to a drug induced down regulation of $\beta$ adrenoceptors and a consequent loss of the ability of the above drugs to stimulate the failing heart. ${ }^{11}$ Xamoterol is a $\beta_{1}$ adrenoceptor partial agonist that modulates the response of the heart to sympathetic stimulation. In patients with ischaemic heart disease, at low levels of sympathetic activity (during rest and modest exercise) the heart receives modest inotropic support, improving both contraction and relaxation, and during high levels of activity the heart is protected against excessive sympathetic stimulation and the consequent ischaemia. Direct evidence for lack of tachyphylaxis was obtained by Pouleur et al who 
showed that the inotropic effect of xamoterol was maintained after 2 months $(200 \mathrm{mg}$ by mouth twice daily). ${ }^{14}$ It is probable that the sustained clinical benefit after 3 months ${ }^{34}$ and 18 months' treatment as shown in this study is related to the particular level of partial agonist activity possessed by xamoterol at the $\beta_{1}$ adrenoceptor and its lack of any agonist activity at the $\beta_{2}$ adrenoceptor ${ }^{67}$-characteristics that distinguish xamoterol from pirbuterol and prenalterol.

Many patients with heart failure have coexisting angina $-72 \%$ in this study. Treatment of patients with heart failure and angina poses a dilemma. ${ }^{15}$ The aim is to relieve the symptoms of congestion and chest pain and to improve pump function and prevent arrhythmias. Treatment to improve cardiac performance by inotropic stimulation may increase ischaemia and treatment with $\beta$ adrenoceptor blockers for ischaemia reduces cardiac contractility and therefore increases the risk of pump failure. Xamoterol improved cardiac performance without an increase in myocardial oxygen consumption, ${ }^{16}$ had antianginal effects ${ }^{17}$ and in this study improved the signs and symptoms of heart failure.

We conclude that xamoterol is an alternative to the conventional treatment of mild to moderate heart failure associated with ischaemic heart disease because it improved exercise tolerance, patient symptoms and activities, and haemodynamic variables and sustained this effect in the long term without side effects or the development of tolerance.

We thank Professor Eva Steiness, Mike Snow, and Margaret Day for valuable advice.

1 Cleveland JGF, Dargie HJ, Ford I. Mortality in heart failure: clinical variables of prognostic value. Br Heart $J$ failure: clinical varis
2 McKee PA, Castelli WP, McNamara P, Kannel WB. The natural history of congestive heart failure. $N$ Engl $J$ Med 1971;285:1441-7.

3 The German and Austrian Xamoterol Study Ğroup. Double-blind placebo-controlled comparison of digoxin and xamoterol in chronic heart failure. Lancet 1988;i:
489-93.

4 Rousseau MF, Pouleur H, Vincent MF. Effects of a cardioselective $\beta_{1}$ partial agonist ('Corwin') on left ventricular function and myocardial metabolism in patients with previous myocardial infarction. Am J Cardiol 1983;51:1267-73.

5 Malajo AO, Bennett DH. Effect of xamoterol (ICI 118 587),

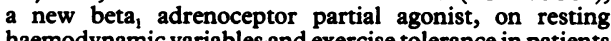
haemodynamic variables and exercise tolerance in patients with left ventricular dysfunction. Br Heart $J$ 1985;54: 17-21.

6 Nuttall A, Snow HM. The cardiovascular effects of ICI 118,587: a $\beta$-adrenoceptor partial agonist. Br J Pharmacol 1982;77:381-8.

7 McCaffrey PM, Riddell JG, Shanks RG. The selectivity of xamoterol, Prenalterol and Salbutamol as assessed by their effects in the presence and absence of ICI 118,551. $J$ Cardiovasc Pharmacol 1988;11:543-51.

8 Packer $M$. Neurohormonal interactions and adaptations in congestive heart failure. Circulation 1988;77:721-30.

9 Vigholt-Sørensen E, Faergeman O, Snow HM. Effects of xamoterol, a $\beta_{1}$ adrenoceptor partial agonist, in patients with ischaemic dysfunction of the left ventricle. Br Heart $J$ 1989;62:335-41.

10 Swerdlow CD, Winkle RA, Mason JW. Determinants of survival in patients with ventricular tachyarrhythmias. N Engl J Med 1983;308:1436-42.

11 Colucci WS, Alexander RW, Williams GH, et al. Decreased lymphocyte beta-adrenergic-receptor density in patients with heart failure and tolerance to the beta-adrenergic with heart failure and tolerance to the beta-adrener

12 Lambertz H, Meyor J, Erbel R. Long-term haemodynamic effects of prenalterol in patients with severe congestive effects of prenalterol in patients with severe

13 Glover DR, Wathen CG, Murray RG, Petch MC, Muir AL, Littler WA. Are the clinical benefits of oral prenalterol in ischaemic heart failure due to beta blockade? A six month randomised double blind comparison with placebo. $\mathrm{Br}$ Heart $J$ 1985;53:208-15.

14 Pouleur H, Hanet C, Gurne O, Rousseau MF. Beneficial effects of $\beta_{1}$-adrenoceptor stabilization and $\beta_{2}$-adrenoceptor blockade with xamoterol in severe ischaemic heart failure treated with ace-inhibitors [Abstract]. J Am Coll Cardiol 1988;11:116A.

15 Heikkila J. The clinical dilemma of the patient with angina pectoris and heart failure. Practical Cardiology 1986; 12:54-66.

16 Pouleur H, Rousseau MF, Mengeot $P$, Veriter C, Vincent MF, Brasseur LA. Improvement of global and regional left ventricular function in patients with previous myocarleft ventricular function in patients with previous myocar-
dial infarction by a new $\beta$,-adrenoceptor partial agonist, dial infarction by a new $\beta_{1}$-adrenocepto

17 Barrios L, Geboers J, Piessens JH, de Geest H. Effects of xamoterol a new beta-adrenoceptor partial agonist in patients with angina pectoris. Eur J Clin Pharmacol 1986;29:667-71. 